\title{
SHOULD PUBLIC HEALTH BE EXEMPT FROM ETHICAL REGULATIONS? INTRICACIES OF RESEARCH VERSUS ACTIVITY.
}

\author{
D. Gitau-Mburu
}

Abstract

Objective: To assess the role of ethical regulations in public health practice, and to review the need to exempt any public health activity from such ethical regulations.

Methods: Literature review of published papers regarding ethical regulations in public health practice.

Results: There is a current criticism of public health ethics as hindering rather than facilitating public health research. There is also an existing dilemma as to which Public health activities constitute research and are therefore subject to ethical regulations and which ones are exempt from such regulations.

Conclusion: Exempting some public health activities from ethical regulation may occasion an inherent risk of subjective interpretation of the criteria guiding the distinction between Public health research and non-research. In order to avoid inadvertent breach of ethical regulations, ethical regulations should be applied to all public health activities whether formally classified as research or not.

\section{Introduction}

The judge in the land mark Nuremberg trial recognized the void that is now filled by research ethics. Ethical regulations are necessary to safeguard the interests of participants in clinical, biomedical and even public health practice. However, it is worthwhile to note the current criticism of 'excessive' ethical regulation, particularly in public health practice. An increasingly large number of researchers argue that stringent ethical regulation sequesters public health research, is impractical (1) obstructive, (2) leads to unnecessary delays, (3) and may even suppress research altogether (4) not forgetting the difficulty of applying them in developing countries (5).

Additionally, there is widespread disquiet and controversy that excessive regulation is a particular threat to research confined to use of medical records (6) and that complying with some of those regulations may lead to erroneous research conclusions (7), thereby effectively invalidating research.

Inevitably, in a pluralistic society, such divergent opinions are bound to arise. In view of the prudence of creating a research-enabling environment, is this criticism of regulation justified? To what extent should public health practitioners restrict application of research regulations in order 'not to hinder research'?

\section{Methods}

A literature review was carried to provide existing evidence for the need to apply ethical regulations in public health as well as the criteria on which exemption of an activity from such ethical regulation may be based.

A database search of Pubmed was carried out between March and June 2008 using the following search terms: ("Public Health"[Mesh] OR public health research [tw] OR Public Health activity [tw] OR "Population Surveillance"[Mesh])) OR surveillance [tw] OR "Epidemiology"[Mesh]) OR ("Contact Tracing/legislation and jurisprudence"[Mesh] OR "Contact

Correspondence: Gitau-Mburu D, Population Services International, Kenya. Fax: (+254) 4440899, Telephone: (+254) 020 4440125, Email address: gitau.mburu@psikenya.org
Tracing/utilization"[Mesh]) AND ("ethics "[Subheading] OR "Code\$ of Ethics"[Mesh] OR "Ethics Committees, Research"[Mesh] OR "Ethics, Research"[Mesh] OR "Ethics, Clinical"[Mesh] OR "Ethics, Medical"[Mesh] OR Public health ethics [title]OR "Ethical Theory"[Mesh])) OR ("Ethical Review/legislation and jurisprudence"[Mesh] OR "Ethical Review/standards"[Mesh]) OR ("Practice Guidelines as Topic"[Mesh] OR "Guideline "[Publication Type] OR "Practice Guideline\$ "[Publication Type]))). Similar articles were assessed using the related articles tool in PubMed.

\section{Results:}

From the literature review, it appears that whereas there are established guidelines for clinical and biomedical research, there are no ethical guidelines specific to public health. Further it is unclear as to what activities constitute research and which ones do not.

Presently the distinction of an activity as either research or non research is based on criteria developed by CDC, which defines research as "a systematic investigation, including research development, testing and evaluation, designed to develop or contribute to generalizable knowledge."

Subsequently, ethical regulation is required for all public health activities that qualify as research within the above definition. Yet, some public health activities may only fulfil the above definition partially. Consequently, and for some public health activities, there is often an existing dilemma on whether they constitute research or not. (8)

Additionally, whereas most contemporary ethical codes address biomedical and research involving human subjects, public health research is usually non-medical, is often based on communities rather than individuals, and may occasionally be limited to review of disease registry data, vital statistics, outbreak investigation or similar surveillance activities.

Emphasis here is that public health bears a societal approach to health, since it improves the well being of communities through social rather than individual interventions. (9) Furthermore, research in public health follows an observational model in which the surveys do not attempt to influence medical interventions, and all they are concerned with is finding patterns in data that are 
consistent and systematic, which in turn can be used to inform decision making whereby the researcher 'does nothing' to the subject.

Arguably therefore, many public health activities do not qualify as research with human subjects, (10) and consequently, owing to its population-based focus, public health faces dilemmas concerning whether its activities infringe on individual autonomy. (9) In any case, are all categories of public health activities research? If not, which activities should be excluded from this definition? Alternatively, should all activities in public health not be considered research, considering that the "society has regarded the benefits as greatly outweighing risks to individuals"? (10) This distinction is important as it determines which activities require ethical regulation such as ethical reviews.

Consider health services research, which is concerned with audit of health services. Should individual informed consent be obtained for such studies? (11) Does the collection and analysis of mortality and morbidity data for example, always constitute research? (12-13)

Mariner (10) argues that activities such as disease surveillance programs which are designed to collect anonymous data do not involve research subjects and pose no threat to patients. There is also an assumption that qualitative research is unlikely to cause significant harm to participants. (14) Does this therefore exempt such activities from ethical regulations?

\section{Discussion}

Based on the above issues, (which are by no means exhaustive) in which the need for research ethics is not straightforward it is acknowledged that there may be cases in which exceptions may plausibly be justified. However, danger lurks in allowing such exceptions in the light of the uncertainty regarding distinction between surveillance, audit, outbreak response, research and so on, and therefore whether a specific activity qualifies for exemption eventually becomes a matter of subjective debate. Indeed, the distinction of research from nonresearch is based on criteria (15) which are themselves liable to different interpretations depending on the researcher's ethical orientation.

It is likely that the reservations held against strict regulation of research emanates from the proponents' ethical discourse, in regard to practical or applied ethics versus normative ethics, a disposition which prompts the critics to pick out a particular research issue and ethically analyze it singularly. With such an approach, there are bound to be activities for which arguments for ethical review may not withstand.

Generally, ethical regulation is required to arbitrate the inevitable tension between the rights of the individuals and those of the common good (13) which arise in the course of public health research.

In addition, even when ethical issues could not possibly have been envisioned by the nature of the research design, ethical issues may arise in the course of the activity itself, since ethical issues are encountered in the course of interaction with others. Therefore, even when the research has been carefully reviewed and no ethical issues are anticipated, a researcher may find himself having to make an urgent ethical decision completely unprepared. Even qualitative research, which may be construed to be harmless exposes participants such risks as anxiety, exploitation, misrepresentation and identification in published papers (14).

Moral issues dominate public health (16), possibly more than is acknowledged, and these issues are bound to become even more prominent as the field of public health grows. Ethical issues may in fact arise with the very choice of public health topic that the researcher chooses to explore. Studies have shown that even research on unlinked anonymous data may also bear ethical dimensions (17). Ethical issues exist even outside the realms of conventional research.

In addition, whether or not the activities are research, it is essential that they be conducted ethically, emphasizing the need for ethical review (18). Indeed, the distinction between research and practice is occasionally illusory.

Furthermore, as Wedeen (19) asserts, "the argument that public research activities are not research because they are not 'designed' to develop 'generalizable' knowledge does not abrogate the obligation of the public health community to protect privacy". This is particularly important because it safeguards against the scenario where an activity may be interpreted and justified using existing guidelines, as either research or non-research by different researchers, owing to their subjective ethical orientations.

Ethical review in any public health activity would ensure that it adheres to existing ethical guidelines. It would also serve as a means of avoiding inadvertent breaches in confidentiality (13). In addition, ethical reviews make public health more effective (from a utilitarian point of view) by raising its standards.

However, ethical regulation only complements other sanctions put in place to deter unethical research, all of which do not guarantee success. As Beecher (20) pointed out in his landmark paper, the ultimate safeguard is the researcher himself, by virtue of him being intelligent, conscientious, compassionate and responsible. In other words, the researcher should advocate what he himself believes to be ethical. (9) Whereas it is entirely proper for ethical codes and declarations to be formulated, they are only valuable if they are used as intended and not as a substitute for the researcher's own conscience. Indeed, it is easy to shelter behind an ethical code to avoid thinking about the real issues. The researcher should not view ethical approval as a 'rubber stamp' to do that which in his own mind is unethical.

\section{Conclusions}

Attention to ethical issues is of paramount importance in all stages of public health programs whether planning, implementation or evaluation, and that doing so will facilitate growth of public health as a discipline. Ethics therefore should be a key consideration for every public health activity, regardless of whether such an activity is believed to be research or not. Additionally, research in public health must be conducted within the confines of internationally accepted as well as local ethical requirements, thus emphasizing on the need 
for ethical overview. Further, in order to sidestep unnecessary ethical problems occasioned by the distinction between public health activity and research, ethical principles should be applied to both.

\section{References:}

1. Tu JV, Willison DJ, Silver FL, Fang J, Richards JA, Laupacis A, et al Impracticability of informed consent in the registry of Canadian stroke network. N Engl J Med 2004 Apr 1;350(14):1414-21.

2. Haddow JE, Palomaki GE. Use of personal records for research purposes. Restrictions unnecessary and obstructive. BMJ. 1995 Jan 28;310(6974):258.

3. Togerson DJ, Domville JC. Ethics review in research: Research governance also delays research. BMJ. 2004 Mar 20;328(7441):710.

4. Hearnshaw H. Variations, across eleven European countries, in research ethics requirements for non-invasive, interventional study. BMJ 2003;327: 140-1.

5. Bhutta ZA. Ethics in international health research: a perspective from the developing world. Bull World Health Organ 2002;80(2): 114-20.

6. Wald N, Law M, Meade T, Miller G, Alberman E, Dickinson J. Use of personal medical records for research purposes. BMJ 1994 Nov 26;309(6966):1422-4.
7. Woolf SH, Rothemich SF, Johnson RE, Marsland DW. Selection bias from requiring patients to give consent to examine data for health services research. Arch Fam Med 2000 Nov-Dec;9(10):1111-8.

8. Hodge JG Jr. An enhanced approach to distinguishing public health practice and human subjects research. J Law Med Ethics. 2005 Spring;33(1):125-41.

9ass NE. An ethics framework for public health. Am J Public Health 200 Nov;91(11):1776-82.

10. Mariner WK. Public confidence in public health research ethics. Public Health Rep. 1997 Jan-Feb;112(1):33-6.

11. Cassell J, Young A. Why we should not seek individual informed consent for participation in health services research. J Med Ethics 2002 Oct;28(5):313-7.

12. Capron AM. Protection of research subjects: do special rules apply in epidemiology? Law Med Health Care. 1991 Fall-Winter;19(3-4):184-90.

13. Fairchild AL, Bayer R. Public health. Ethics and the conduct of public health surveillance. Science. 2004 Jan 30;303(5658):631-2.

14. Richards HM, Schwartz LJ. Ethics of qualitative research: are there special issues for health services research? Fam Pract. 2002 Apr;19(2):135-9.

15. Centers for Disease Control and Prevention. Defining Public Health Research and Public Health Non-Research. [Online].1999 October 4. [Cited $\begin{array}{lll}\text { Research and Public Health Non-Research. [Online].1999 October 4. [Cited } \\ \text { May } & 18 & \text { 2008] }\end{array}$ http://www.cdc.gov/od/science/regs/hrpp/researchDefinition.htm

16. Callahan D, Jennings $B$. Ethics and public health: forging a strong relationship. Am J Public Health. 2002 Feb;92(2):169-76.

17. Nicoll A, Gill N, Goldberg D, Peckham C. The ethics of unlinked anonymous testing. Surveys provide essential information.BMJ. 2000 May 6;320(7244): 1275 .

18. MacQueen KM, Buehler JW.Ethics, practice, and research in public health.Am J Public Health. 2004 Jun;94(6):928-31.

19. Wedeen RP. Ethics in public health institutions. Am J Public Health. 2002 Dec;92(12): 1884-5.

20. Beecher HK. Ethics and clinical research. N Engl J Med. 1966 Jun $16 ; 274(24): 1354-60$. 